\title{
Delivering a medical school elective with massive open online course (MOOC) technology
}

\author{
Robert Robinson ${ }^{\text {Corresp. } 1}$ \\ ${ }^{1}$ Internal Medicine, Southern Illinois University School of Medicine \\ Corresponding Author: Robert Robinson \\ Email address: rrobinson@siumed.edu
}

Introduction: The educational technology of massive open online courses (MOOCs) has been successfully applied in a wide variety of disciplines and are an intense focus of educational research at this time. Educators are now looking to $\mathrm{MOOC}$ technology as a means to improve professional medical education, but very little is known about how medical MOOCs compare with traditional content delivery.

Methods: A retrospective analysis of the course evaluations for the Medicine as a Business elective by fourth year medical students at Southern Illinois University School of Medicine (SIU-SOM) for the 20122015 academic years was conducted. This course was delivered by small group flipped classroom discussions for 2012-2014 and delivered via MOOC technology in 2015. Learner ratings were compared between the two course delivery methods using routinely collected course evaluations.

Results: Course enrollment has ranged from 6-19 students per year in the 2012-2015 academic years. Student evaluations of the course are favorable in the areas of effective teaching, accurate course objectives, meeting personal learning objectives, recommending the course to other students, and overall when rated on a 5 point Likert scale. The majority of all student ratings (76\%-95\%) of this elective course are for the highest possible choice (Strongly agree or Excellent) for any criteria, regardless if the course was delivered via a traditional or MOOC format. Statistical analysis of these ratings suggests that the Effective Teacher and Overall evaluations no not statistically differ between the two delivery formats.

Discussion: Student ratings of this elective course were highly similar when delivered in a flipped classroom format or by using $\mathrm{MOOC}$ technology. The primary advantage of this new course format is flexibility of time and place for learners, allowing them to complete the course objectives when convenient for them. The course evaluations suggest this is a change that is acceptable to the target audience.

Conclusions: This study suggests that learner evaluations of a fourth year medical school elective course do not significantly differ when delivered by flipped classroom group discussions or via MOOC technology in a very small single center observational study. Further investigation is required to determine if this delivery method is an acceptable and effective means of teaching in the medical school environment. 
1 Delivering a medical school elective with massive open online course technology

2 Author

3 Robert Robinson, MD

4 Department of Internal Medicine

5 Southern Illinois University School of Medicine

6 Springfield, IL USA

7

8 
Introduction

11 The educational technology of massive open online courses (MOOCs) has been successfully

12 applied in a wide variety of disciplines and are an intense focus of educational research at this

13 time (Bozkurt et al, 2015). MOOCs are a disruptive force in education because they challenge

14 the tradition of lectures and decentralize the education experience in a learner centered way.

15 Learners have embraced this approach, giving some MOOCs an enrollment of over 100,000

16 (Mehta, Hull, Young, and Stoller 2013). Educators are now looking to MOOC technology as a

17 means to improve professional medical education (Harder 2013, Mehta; Hull, Young, and Stoller 18 2013).

20 Hundreds of medical MOOCs exist for topics ranging from the Ebola virus to medical informatics

21 (Grobusch and Browne 2015; Paton 2014; Liyanagunawardena and Williams 2014), but very

22 little is known about how these medical MOOCs compare with traditional content delivery.

24 MOOC delivery platforms allow educators to create and deliver interactive courses with videos, 25 online resources, quizzes, virtual patients (Stathakarou, Zary, and Kononowicz 2014;

26 Kononowicz et al., 2015 ) and an ability to interact with other students taking the course. This 27 technology could allow students to learn at a time and place of their choosing, freeing valuable 28 curricular time for hands on experiences. Despite these potential advantages, medical schools 29 have been slow to explore MOOC technology for content delivery. 
31 This study aims to compare learner evaluations and ratings of a course that was previously

32 delivered by traditional methods (in person lecture and case discussions) that is now delivered

33 as a MOOC. The hypothesis is that learner ratings of the course will not significantly differ

34 between the new format and the previous format. The results of this investigation could have

35 significant implications for how medical education is delivered.

37 Materials \& Methods

38 Course evaluations for the Medicine as a Business elective (Course IM 45434) by fourth year

39 medical students at Southern Illinois University School of Medicine (SIU-SOM) were collected

40 as customary for the $2012-2015$ academic years. The SIU-SOM is located in Springfield,

41 Illinois.

42 The Medicine as a Business course was offered for the first time in the 2012 academic year and

43 used small group flipped classroom format as an extended nonclinical elective at SIU-SOM.

44 Extended electives are non-overlapping and are scheduled on Thursday afternoons in 5 week

45 blocks at SIU-SOM. The Medicine as a Business course could start every 5 weeks during the

46 academic year if two or more students wished to enroll in a specific 5 week block. Attendance

47 and participation in all discussions was required for successful course completion.

48 This course was converted to an on demand MOOC format hosted at Udemy.com for the 2015

49 academic year to meet student requests for greater flexibility in course content delivery.

50 Course content is delivered in the form of video presentations with associated reading materials

51 and multiple choice questions that could be accessed on a smartphone, tablet, or traditional

52 computer via the internet when convenient for the student. Completion of all course sections

53 was required for successful completion of the course. Each student started and completed the

54 course independently and had the option of meeting with the faculty to discuss course content. 
55 The MOOC content delivery system included a system to send messages to the course

56 instructor and a discussion forum accessible by learners.

57 The objectives for Medicine as a Business are:

58

59

60
Understand and apply medical documentation rules

Understand the medical billing process

Understand medical coding terminology and resources

Understand the medical practice revenue cycle

Evaluate physician productivity using a variety of measures

The course is available online at http://udemy.com/business-of-medicine. Course registration is free and open to anyone.

SIU-SOM compiles de-identified aggregate course evaluations for elective faculty for use in course improvement. These course evaluations were compared before and after transition to the MOOC format and do not include any demographic data for the students enrolled. This data was compared for differences between traditional and MOOC based content delivery.

The SIU-SOM elective course evaluation includes:

- Was the faculty an effective teacher?

- Stated course objectives accurately reflected the course.

- I was able to meet my personal learning objectives.

- I would recommend this elective to other students.

- Overall rating of the course.

These items are rated on a 5 point Likert scales.

The rating scale for the overall course rating was $1=$ Poor, 2 = Below average, $3=$ Average, $4=$ Above average, $5=$ Excellent.

The rating scale for all other measures was 1 = Strongly disagree, 2 = Disagree, $3=$ Neither agree or disagree, 4 = Agree, 5 = Strongly agree. 
81 Differences between items in the course evaluation questions will be compared with the t-test to 82 determine if any significant differences exist.

83 Statistical analyses were performed using SPSS version 22 (SPSS Inc., Chicago, IL, USA).

84 Two sided $P$-values $<0.05$ were considered significant.

85 Cohen's d was calculated for each result using Cohen's d calculator for unequal sample sizes

86 developed by Dr. Jeremy Stangroom (Stangroom 2016).

87 Post-hoc power analysis was conducted with a Post-hoc Statistical Power Calculator for a

88 Student t-Test developed by Dr. Daniel Soper (Soper 2016).

89 Institutional review board review for this study was obtained from the Springfield Committee for

90 Research Involving Human Subjects. This study was determined to not meet criteria for

91 research involving human subjects according to 45 CFR 46.101 and 45 CFR 46.102.

93 Results

94 The Business of Medicine elective has been offered for four years at SIU-SOM starting in the

952012 academic year. The size of the fourth year class at SIU-School of Medicine ranged from

9669 to 75 students during the study period. Women made up $45-54 \%$ of the fourth year class

97 during that timeframe (Table 1). Course enrollment has ranged from 6-19 students per year as

98 shown in Figure 1 and Table 1.

99 Student evaluation distributions by course format (MOOC vs. Traditional) for the evaluation

100 criteria of Effective Teacher (Figure 2), Course Objectives Accurate (Figure 3), Met Personal

101 Objectives (Figure 4), Recommend Course (Figure 5), and Overall Evaluation (Figure 6) are

102 skewed towards the highest rating and are very similar. No negative course ratings (Disagree,

103 Strongly disagree, Poor, or Below average) were reported for any course evaluation. The 
104 majority of all ratings (76\%-95\%) are for the highest possible choice (Strongly agree or 105 Excellent).

106 Student evaluations by course format (MOOC vs. Traditional) show no statistically significant 107 differences ( $p=$ NS for all criteria, Table 2). A medium or greater effect sizes were seen for the 108 Effective Teacher (Cohen's d = 0.782), Met Personal Objectives (Cohen's $d=0.593$ ), and 109 Overall Evaluation (Cohen's $d=1.496$ ) criteria. Small effect sizes were seen for the Course 110 Objectives Accurate (Cohen's d = 0.460) and Recommend Course to other students (Cohen's d $111=0.490)$ criteria. Post-hoc power analysis indicated the results for Effective Teacher (99\%) and 112 Overall evaluation (92\%) had greater than $80 \%$ power to correctly reject the null hypothesis.

113 The results for all other criteria did not have sufficient power to correctly reject the null 114 hypothesis. 
117 Figure 1. Student enrollment in the Medicine as a Business elective by academic year.

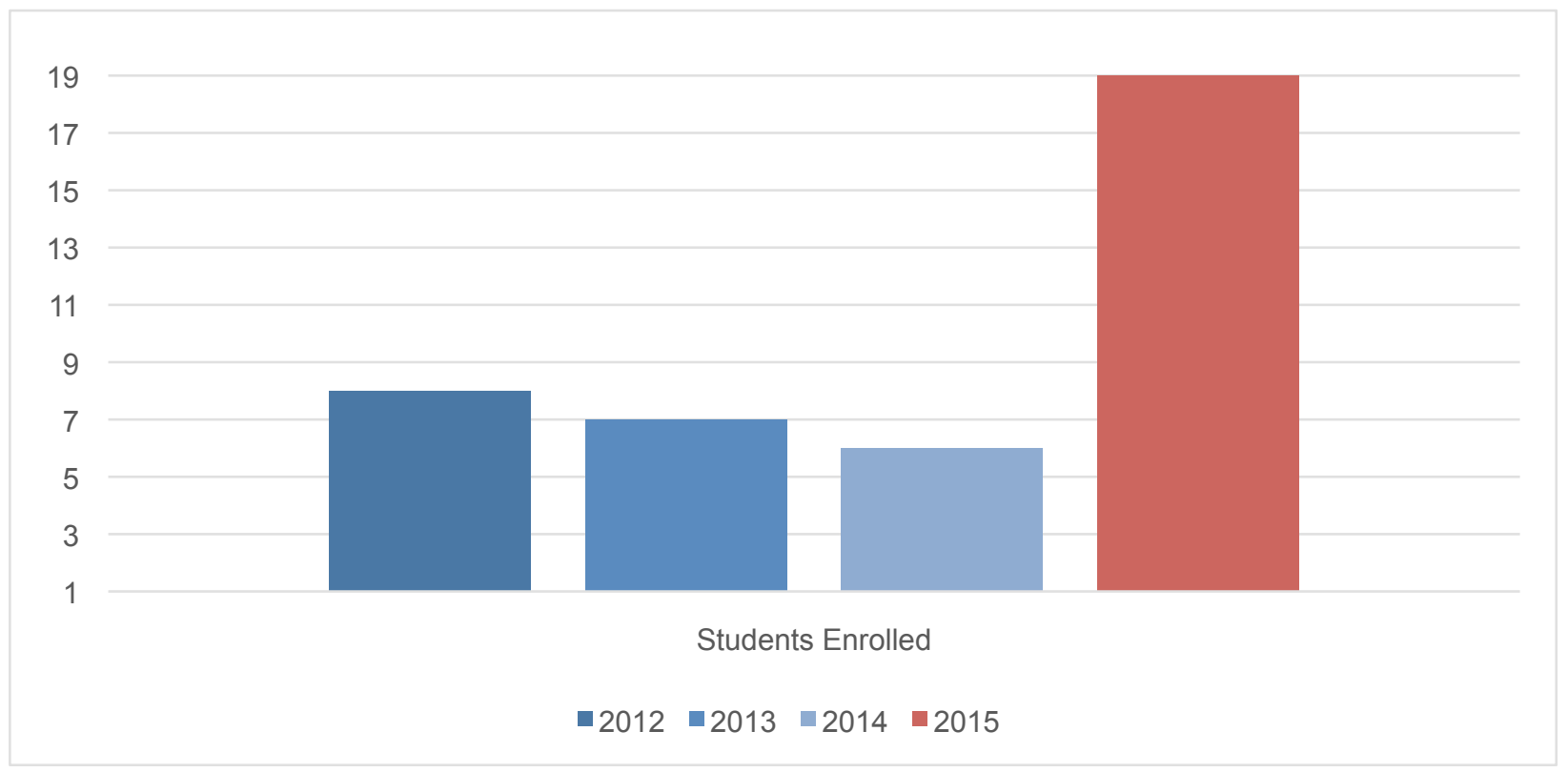


121 Figure 2. Student ratings for "Was the course faculty an effective teacher?" by course format

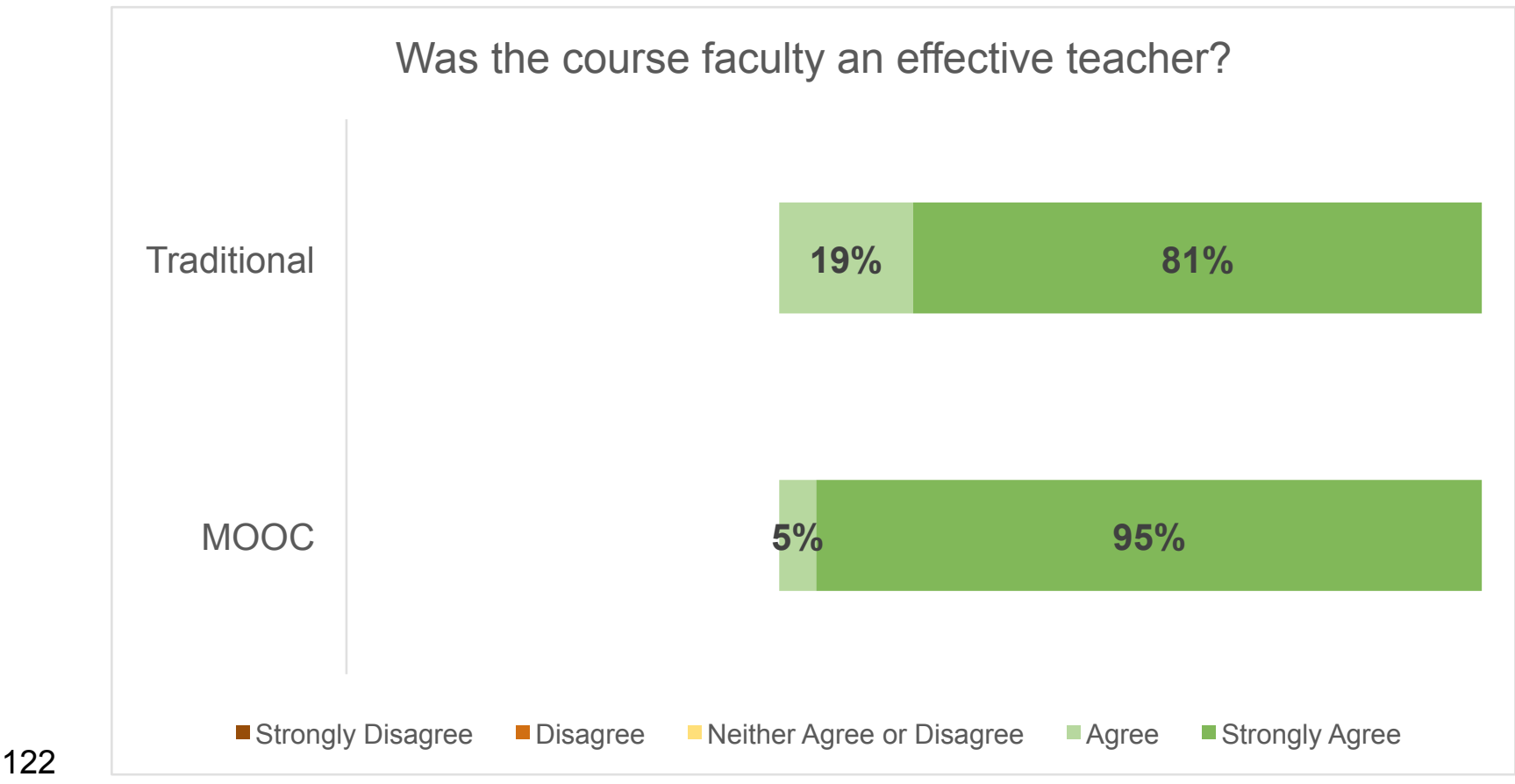


126 Figure 3 . Student ratings for "Stated course objectives accurately reflected the course" by

127 course format

Stated course objectives accurately reflected the course

$5 \% 16 \%$

Traditional

MOOC

\section{$5 \% 16 \%$}

$79 \%$

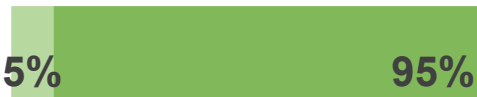

$95 \%$ 
132 Figure 4. Student ratings "I was able to meet my personal learning objectives" by course format

I was able to meet my personal learning objectives

$5 \% 16 \%$

Traditional

MOOC

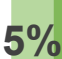

$95 \%$

134 
138 Figure 5. Student ratings "I would recommend this elective to other students" by course format

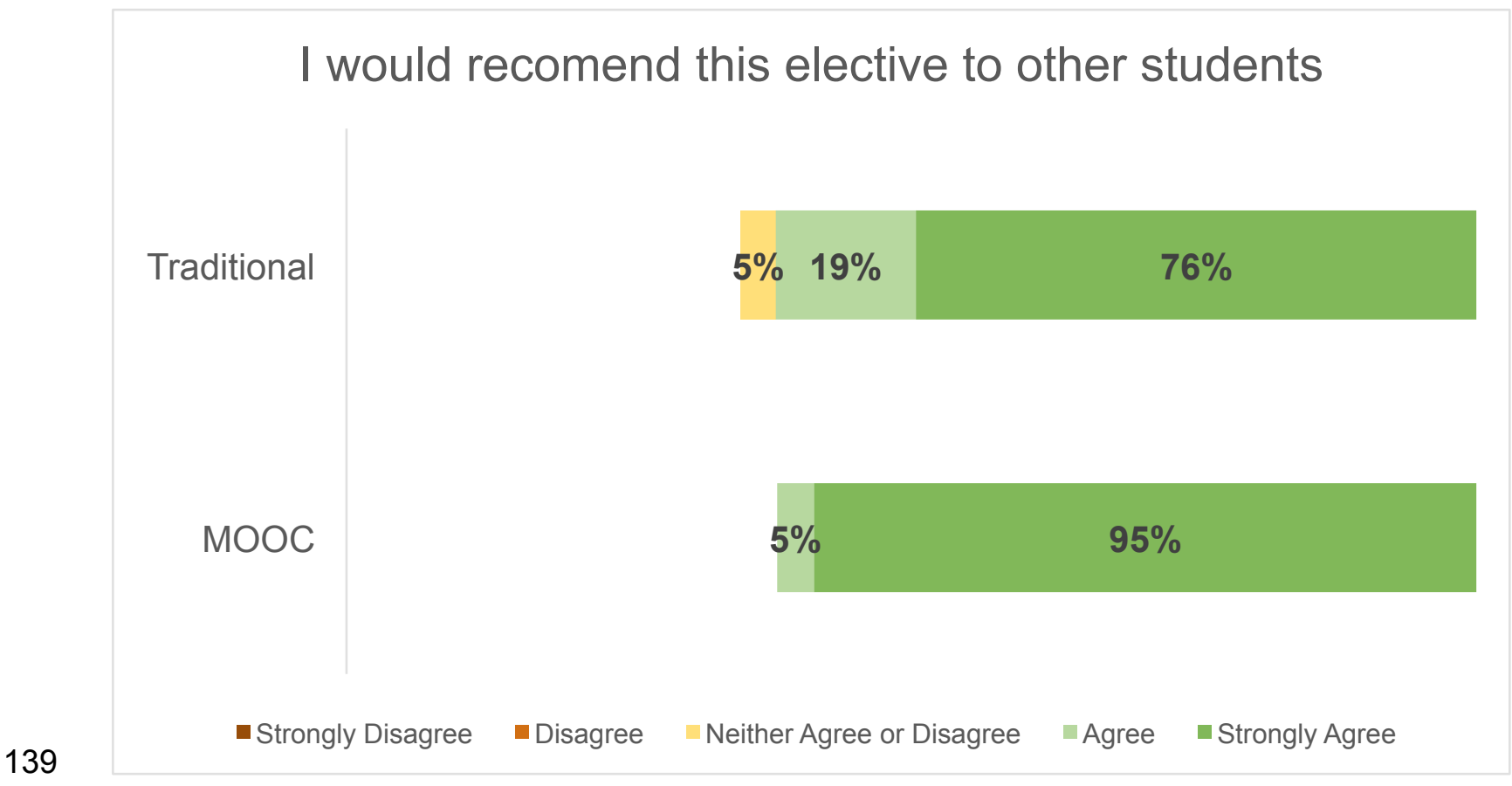


143 Figure 6. Student ratings for Overall Evaluation by course format

Overall course rating

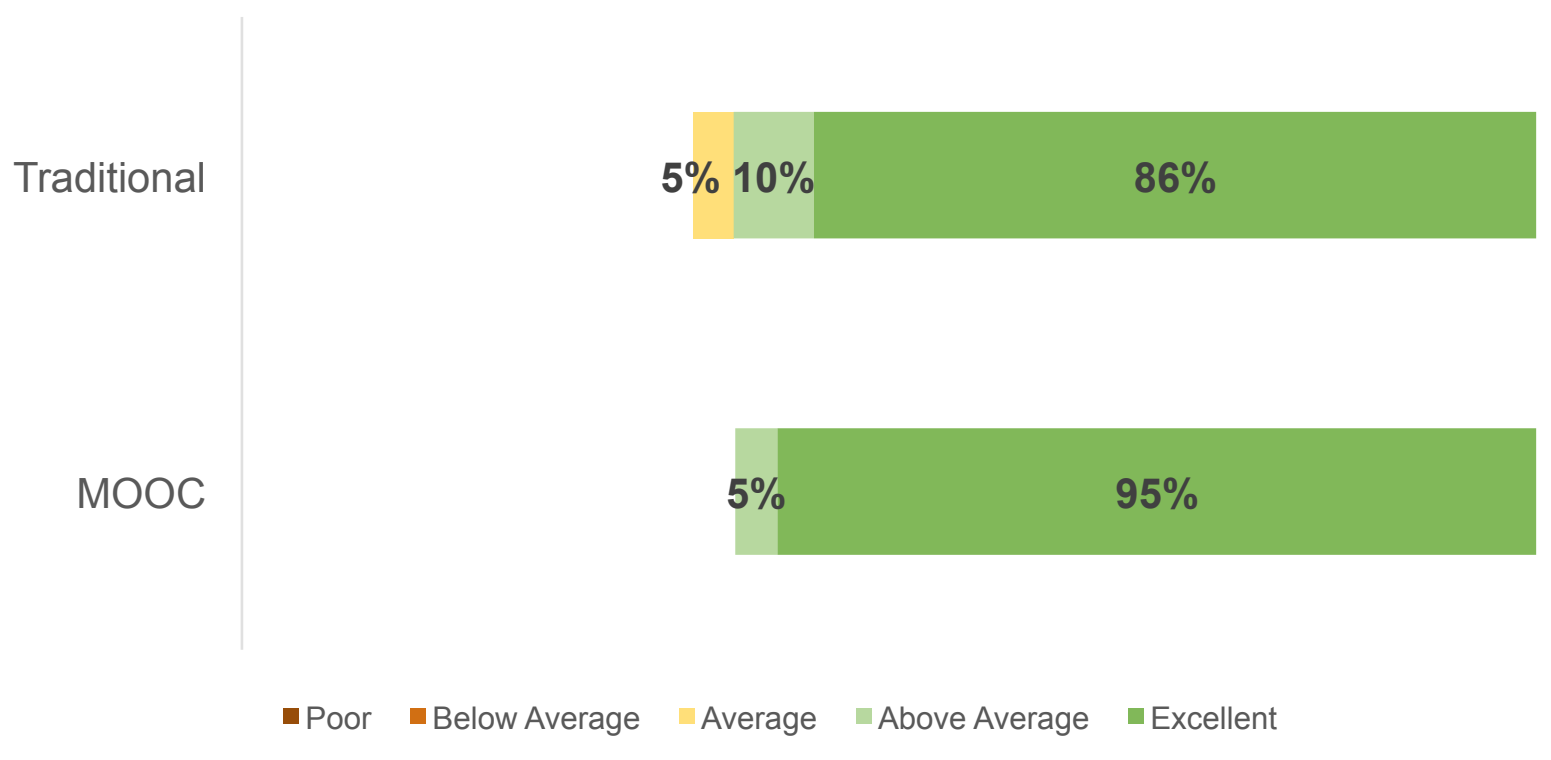


149 Table 1. Fourth year medical student demographics by year

\begin{tabular}{|l|l|l|l|} 
Year & Students & Women & $\begin{array}{l}\text { Students enrolled in Medicine as a Business } \\
\text { elective }\end{array}$ \\
\hline 2012 & 72 & $34(47 \%)$ & $8(11 \%)$ \\
\hline 2013 & 75 & $35(47 \%)$ & $7(9 \%)$ \\
\hline 2014 & 69 & $31(45 \%)$ & $6(9 \%)$ \\
\hline 2015 & 70 & $38(54 \%)$ & $19(27 \%)$ \\
\hline
\end{tabular}

150

151

152

153

154 
155 Table 2. Student course ratings by course format (MOOC vs. Traditional)

$\begin{array}{ll}\text { Traditional } & \text { MOOC } \\ \text { Mean (SD) } & \text { Mean (SD) }\end{array}$

\begin{tabular}{|c|c|c|c|c|c|}
\hline Rating & $N=21$ & $N=19$ & Significance & Power & Cohen's d \\
\hline Overall evaluation & $\begin{array}{l}4.81 \\
(0.512)\end{array}$ & $4.5(0.229)$ & 0.287 & $92 \%$ & 0.782 \\
\hline $\begin{array}{l}\text { I would recommend } \\
\text { this elective to other } \\
\text { students }\end{array}$ & $\begin{array}{l}4.71 \\
(0.561)\end{array}$ & $4.5(0.229)$ & 0.100 & $45 \%$ & 0.490 \\
\hline $\begin{array}{l}\text { I was able to meet } \\
\text { my personal learning } \\
\text { objectives }\end{array}$ & $\begin{array}{l}4.75 \\
(0.550)\end{array}$ & $4.5(0.229)$ & 0.156 & $67 \%$ & 0.593 \\
\hline $\begin{array}{l}\text { Stated course } \\
\text { objectives } \\
\text { accurately reflected } \\
\text { the course }\end{array}$ & $\begin{array}{l}4.70 \\
(0.571)\end{array}$ & $4.5(0.229)$ & 0.087 & $39 \%$ & 0.460 \\
\hline $\begin{array}{l}\text { Was the course } \\
\text { faculty an effective } \\
\text { teacher? }\end{array}$ & $\begin{array}{l}4.90 \\
(0.301)\end{array}$ & $4.5(0.229)$ & 0.620 & $99 \%$ & 1.496 \\
\hline
\end{tabular}




\section{Discussion}

160 The majority of all student ratings (76\%-95\%) of this elective course are for the highest possible 161 choice (Strongly agree or Excellent) for any criteria, regardless if the course was delivered via a 162 traditional or MOOC format. Statistical analysis of these ratings suggests that the Effective 163 Teacher and Overall evaluations no not statistically differ between the two delivery formats.

165 The primary advantage of this new course format is flexibility of time and place for learners, 166 allowing learners to take the course when and where convenient for them instead of in 5 week 167 blocks on campus. The course evaluations suggest this change is acceptable to the target 168 audience.

170 Enrollment in this nonclinical elective was good, ranging from 9-27\% of the students each year.

171 It is unclear why course enrollment was highest during the 2015 academic year $\left(27 \%\right.$ of all $4^{\text {th }}$ 172 year students taking the elective). This increase in enrollment may also be accompanied by

173 other demographic changes in the students taking this elective course that may influence

174 course ratings. However, specific student demographics (gender, race, residency choice, and

175 other factors) are not available for analysis to protect the anonymity of students enrolled in this 176 course. 
178 The rating system used for electives at SIU-SOM are not ideal to evaluate a course delivered in

179 this manner. However the highly similar Effective Teacher and Overall course ratings are likely

180 to represent an acceptance of the course format change.

181 The course subject, the business aspects of a medical practice, is likely to be more amenable to

182 delivery via MOOC technology than many other subject areas in medical education. However,

183 the University of California-San Francisco (UCSF) has successfully offered a clinical problem

184 solving MOOC with tens of thousands of learners, suggesting that complex clinical education

185 can be delivered by this format (Harder 2013).

186 The numbers of students enrolled in this course before and after the change to the MOOC

187 format are very small, increasing the risk of a Type 2 error due to insufficient statistical power.

188 Post hoc power analysis showed a range of power from $39 \%$ to $99 \%$ for the evaluation criteria.

189 Only two measures, Effective Teacher and the Overall evaluation, had sufficient power to

190 correctly reject the null hypothesis. Challenges with statistical power reflect the small sample

191 size in this study and a course rating distribution strongly skewed towards the highest rating for

192 all areas evaluated.

194 This study is a single institution observational study with limited follow up. These limitations

195 may reduce the generalizability of the results of this study.

197 Conclusions

198 This study suggests that learner evaluations of a fourth year medical school elective course may

199 not significantly differ when delivered in flipped classroom discussion or via MOOC technology

200 in a very small single center observational study. 
201 Further investigation is required to determine if this delivery method is an acceptable and 202 effective means of teaching in the medical school environment. 


\section{References}

205 Bozkurt, A., Akgun-Ozbek, E., Onrat-Yilmazer, S., Erdogdu, E., Ucar, H., Guler, E., Sezgin, S., 206 Karadeniz, A., Sen, N., Goksel-Canbek, N., Dincer, G. D., Ari, S., \& Aydin, C. H. (2015). Trends 207 in Distance Education Research: A Content Analysis of Journals 2009-2013. International 208 Review of Research in Open and Distributed Learning, 16(1),330-363.

210 Grobusch MP, Browne JL. A Massive Open Online Course (MOOC) to support the fight against 211 Ebola. Travel Med Infect Dis. 2015 May-Jun;13(3):263. doi: 10.1016/j.tmaid.2015.03.015. Epub 2122015 Apr 4.

214 Paton C. Massive open online course for health informatics education. Healthc Inform Res. 215 2014 Apr;20(2):81-7. doi: 10.4258/hir.2014.20.2.81. Epub 2014 Apr 30.

217 Liyanagunawardena TR, Williams SA. Massive open online courses on health and medicine: 218 review. J Med Internet Res. 2014 Aug 14;16(8):e191. doi: 10.2196/jmir.3439.

Harder B. Are MOOCs the future of medical education? BMJ 2013 Jan;346:f2666.

222 Mehta NB, Hull AL, Young JB, Stoller JK. Just imagine: new paradigms for medical education. 223 Acad Med 2013 Oct;88(10):1418-1423. 
224 Stathakarou N, Zary N, Kononowicz AA. Beyond XMOOCs in healthcare education: study of the 225 feasibility in integrating virtual patient systems and MOOC platforms. PeerJ 2014;2:e672

227 Kononowicz AA, Berman AH, Stathakarou N, McGrath C, Bartyński T, Nowakowski P, Malawski

228 M, Zary N. Virtual Patients in a Behavioral Medicine Massive Open Online Course (MOOC): A 229 Case-Based Analysis of Technical Capacity and User Navigation Pathways. JMIR Medical 230 Education 2015;1(2):e8

231 Stangroom, J. Effect Size Calculator for T-Test [Software]. 2016. Available from 232 http://www.socscistatistics.com/effectsize/Default3.aspx

234 Soper, D.S. Post-hoc Statistical Power Calculator for a Student t-Test [Software]. 2016.

235 Available from http://www.danielsoper.com/statcalc 